\title{
Knowledge Management of Thai Local Food on the Route of Northern Tourism in Thailand
}

\author{
Narong Sompong and Nattaphon Rampai
}

\begin{abstract}
The objectives of this research were to: 1) collect, analyze, and synthesize the knowledge about Thai local food along the route of northern tourism and culture that focus on value creation according to local based Thai food with the knowledge management approach; 2) analyze the recipes and the Thai local food along the route of northern tourism in 14 provinces; 3 ) develop the database website and media on Thai local food along the route of northern tourism that is appropriate with the community and support sustainable tourism; and 4) to evaluate the database website and media on Thai local food along the route of northern tourism by tourist groups.

This research study was conducted in the upper and the lower regions of northern Thailand which included 8 provinces. The respondents were purposively selected which involved local people in northern communities, owners of local food restaurant, scholars in tourism industry management, tourists, and selected government officials in the cuisine and tourism sectors. The research methodology was guided by the knowledge management five stages model.

The research findings showed that Thai local food in the Northern regions depicted a fruitful image and identity of history and human diversity. This showed the worth and value for promotion as tourist destination. The gastronomy tourism were developed into 5 routing and the possibility of using local food in the Northern region of Thailand to promote tourism industry was at a high level. The results of expert's opinion on the model was at a high level as well as the evaluation of tourists' opinion on website and mobile application.
\end{abstract}

Index Terms-Thai local food, knowledge management, Northern tourism, media development, mobile application.

\section{INTRODUCTION}

Tourism has a vital role in the service industry sector in the economic systems of Thailand because it does not only generate income up to the first majority of the country but also create an engaged business industry such as hotels and other lodging business, restaurants and catering services, souvenir store, and transportation units. Most of the income of the tourism business comes from souvenir store and hotel, followed by food businesses [1]. Food is the basic commodity in the human life, therefore it is an opportunity to bring about the tourism promotion. Most of the tourists normally need to taste the local food of the community during their journey.

Surachai Jewcharoensakul [2] revealed that half of the tours' companies in Thailand (43.94\%) were established in

Manuscript received May 5, 2014; revised July 7, 2014.

N. Sompong and N. Rampai are with the Department of Educational Technology, Kasetsart University, Bangkok, Thailand (e-mail: fedunrs@ku.ac.th, fedunpra@ku.ac.th).
Bangkok and central part of Thailand. Most of the tourists always stop in Bangkok, then extend traveling to the country side later, and more than one third (35.42\%) were established in the South, due to the good reputation of tourist destination with, beautiful natural resource and peaceful beach. On the other hand, Northern region of Thailand, had divided into 2 parts of upper Northern provinces included 8 provinces, whereas had related history of Lanna territory, Chiengmai was the capital in upper provinces and Pitsanulok was the central city in the lower part.

Thai food is the uniqueness taste and dominant differing from the other countries in the world and could be a part of cultural identities accumulation since the ancient time. According to the CNNGo ranking for the "World's 50 most delicious foods", Thai food menu as "Massamun" became to be the most delicious food in the world [3]. Thai government had launched policy "Thai Kitchen to the World Project" since 2004 in order to achieve the increasing of Thai restaurants from 6,875 to 20,000 worldwide in 2008 and became to be the largest food exporter among 1-5 trade ranking of the world within 2-3 years [4]. The strategic plan of Thailand to develop the sustainable tourism during 2012-2016 were implemented to compete among the Asian Economic Community (AEC). One strategy to pursue this plan was to provide new resources for tourists. A research project on the Knowledge Management in local food of the northern region would be useful for stakeholders who could be searching, sharing, applying, and storing the local Thai cuisine knowledge inside and outside the community through website and application in smart phone and tablet. Therefore, this research would find out and manage the knowledge on local food along the routes of Northern Tourism which would be provided for tourists and the business sectors both in local and national levels.

\section{OBJectives}

1) To collect, analyze, and synthesize the knowledge about Thai local food along the route of northern tourism and culture to local based Thai food with the knowledge management approach;

2) To analyze the recipes and the local food along the route of northern tourism in 14 provinces;

3) To develop the database website and integrated media on Thai local food along the route of northern tourism that is appropriate with the community and support sustainable tourism; and

4) To evaluate the database website and media on Thai local food along the route of northern tourism by tourist groups. 


\section{SCOPE OF THE STUDY}

This study only covered 14 provinces in Northern Thailand with 8 provinces in the upper northern area where the Lanna Cultural Center could be found, and 6 provinces in the lower northern area. This included Chiang Mai, Chiang Rai, Lamphun, Lampang, Phrae, Nan, Mae Hong Son, Phayao, Kamphaeng Phet, Tak, Sukhothai, Phitsanulok, Uttaradit, and Phetchabun. The knowledge collection, analysis and synthesis used the knowledge management procedure to cover the local food in 18 provinces.

Local Thai food knowledge set for public relation composed of 4 main issues: 1) Northern Thai cuisine on cultural history and tradition, 2) ingredients and methods of cooking food, and values of local Northern Thai food, 3) the suitable local food along the route of Northern Thailand in compatible with the indigenous identities and seasons, and 4) the value of healthy food.

\section{THEORIES SUPPORTED IN THE STUDY}

In this study, knowledge management (KM) refers to the process of data and information manipulation for knowledge construction by collecting data from the respondents through survey questionnaires and other resources and then transformed in various media before sharing to the community or organization. In this study, the researchers created the knowledge management process in the five stages explore and capture, identify and organize, exchange and apply, transfer and share, and collect and store. These stages were implemented to manage the local Northern Thai food which is the indigenous knowledge in the community.

\section{RESEARCH Methodology}

This study used the mix methods research design. Quantitative methods included the use of survey and media testing techniques while qualitative methods included the conduct of interviews, observing the key informants, and focus group discussion with the experts. The research methodology was guided by the knowledge management five stages model. The data were collected using two approaches: the construction of Thai local food knowledge along the route of northern tourism, and the development of knowledge packages and integrated media on Thai local food.

This research study was conducted in the upper and the lower regions of northern Thailand which including 8 provinces-Chiang Mai, Chiang Rai, Lamphun, Lampang, Phrae, Nan, Mae Hong Son, and Phayao, Kamphaeng Phet, Tak, Sukhothai, Phitsanulok, Uttaradit, and Phetchabun. The respondents came from purposive sampling which composed of local people in northern communities, the owners of Thai local food, scholars in tourism industry management, tourists, and the selected government officials in the tourism sector.

Sample groups were purposively selected to cover four groups of respondents in 14 provinces in northern Thailand. Overall, there were 34 community leaders, 195 restaurant owners in the remote area, 36 academic persons in the tourism and business industries, 1,018 tourists in three selected provinces (Chiang Rai, Chiang Mai, and Pitsanulok), and 491 government officers and private staff in the food institution and tourism organization.

The research instruments used in this study composed of two interview questionnaires for experts and tourists and local Thai food survey. Digital sound recorders, digital camera and video camera were used to collect data. GPS in Decimal Degree Systems was used to find the locations of restaurants and popular tourist places in the northern region of Thailand. After the expert verified the information gathered, the integrated media was produced in the database on website www.thailocalcuisine.com, and developed into a video presentation, publication, and mobile application. The mobile application "thailocalcuisine" for iOS smart phone and tablet could be downloaded from app store. The data from Global Position System device was designed and put into the website and mobile application. Therefore, restaurants' positions and linked information could be searched on smart phone and tablet as well as on website. Tourists could find the name of restaurant and location shown on the map. Lastly, five routes video production had been produced and upload on YouTube. Every media had been launched for testing by the tourists at the proper places for example airport, hotel, bus station and the most popular tourist places in 3 Northern provinces of Thailand.

Data collection was conducted following the five stages of five stages KM Model which develop by researcher as following procedure. (Henrie and Hedgepeth [5], Nonaka and Takeuchi [6], Vichan Panich [7], and Pravet Vasri [8].

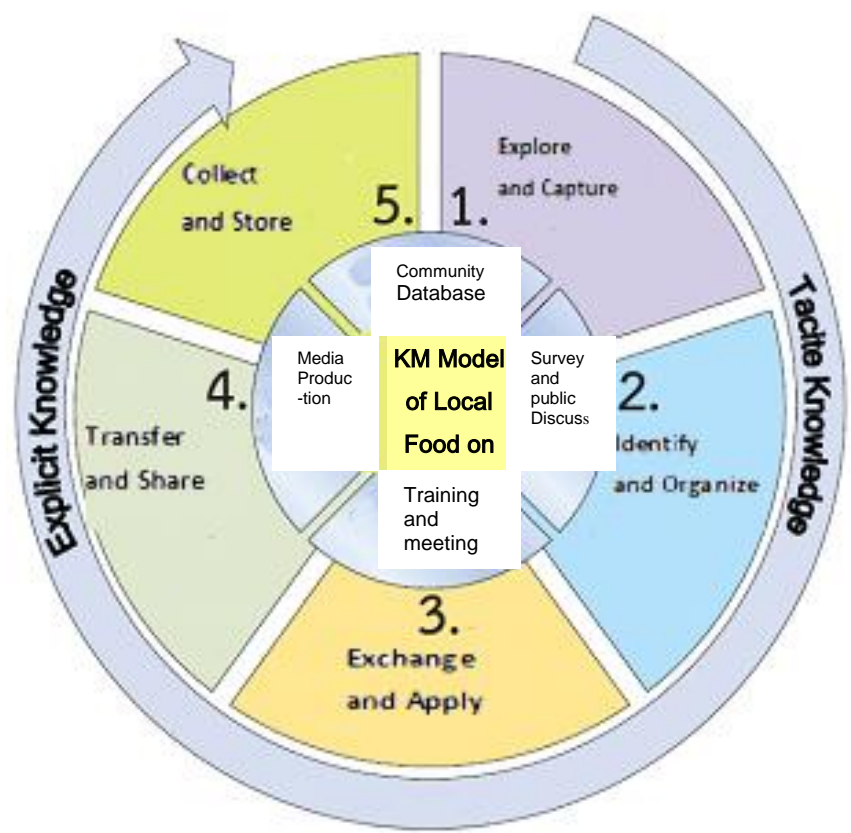

Fig. 1. The model of KM along the route of northern tourism.

Fig. 1 shows the five stages of the KM model. It presents how to find out the tacit and explicit knowledge in local areas. The focus of this study is on the local food of Northern Thailand.

1) Explore and capture. This stage studied relevant documents about the basic knowledge of local Thai food and explores the knowledge in the community. Data were collected using a survey on the best practices of the respondents in the community such as the name of food, food history or mythology, value and culture of the local 
food. The target group included community leaders, owners and scholar in the institutes. Data gathered were clarified by the research team.

2) Identify and organize. This stage focused on the details of the coming data and information to refer and verify for grouping the content. Researchers conducted a focus group with scholars and community leaders as well as in-depth interviews with local philosophers and indigenous people in the remote area.

3) Exchange and apply. The researchers set up a small discussion group meeting in the field (public forum) about knowledge gain. The knowledge was exchanged and applied using information technology and social media in the community.

4) Transfer and share. The researchers acted as facilitators in transferring and sharing the knowledge after improving and revising it. When the knowledge in the local food had been collected, the content would be applied to construct the specific media. In this stage, the researchers planed and developed media integration in website, application, poster, video and publication for knowledge sharing. Five video programs showing 5 routes of Northern tourism were produced and uploaded in website www.thailocalcuisine.com and YouTube:

Route 1 Gateway to "Lanna",

Route 2 Window to visit the northern part of Thailand,

Route 3 Pay respect to the Buddha and visit the dynasty heritage.

Route 4 Visit the peaceful and tranquil heritage.

Route 5 Visit Thailand's border without bounder.

5) Collect and store. The knowledge could be refined and kept into the database clearly in four main issues: 1) Northern Thai cuisine on cultural history and local tradition, 2) cooking food methods and ingredients and values of local Northern food, 3) the suitable local food on the northern route of Thailand in compatible with indigenous identity and seasons, and 4) the value of healthy Thai local food.

Statistical data were analyzed using frequencies, percentages, means, and standard deviation.

\section{RESUlT OF THE STUDY}

1) The Body of Knowledge on Northern Local Food in Thailand

- The identity of the local northern food could be used for tourist promotion in terms of "Gastronomy Tourism" because it is rich in history, legend, with the various indigenous culture and human diversity in different area such as Thai Lue, Thai Yai, and Thai Yuan. This influenced the local food taste and unique diversity which could attract the tourist attention to taste when they take travel along the Northern tourist routes of Thailand.

- The way of life of the people in the community could reflect the food consumption and livelihood of the people and depend on the location, climate, seasons, natural resources, religious practice, and culture. These factors had an influence on the food ingredients, food recipes, and processes in food creation. The knowledge findings showed the phenomenon of the difference of food ingredients and recipes as the local wisdom in food adaptation to their environment and tribal culture.

- From the results of in-depth interview to the indigenous leaders and experts focus group, the research found out that there was a high potential in the local Northern food along the route of Northern tourism in Thailand, especially "Lanna culture" in upper northern provinces. Many food recipes were displayed on table tops in local restaurants, especially along the way to and around the tourist places. In addition, findings showed that aside from the most popular food menu among Thais and foreigner tourists, some food menu that were never shown on the table top in the restaurant should be promoted in the specific seasons. For example, Pak Gard Jor, Pak Cheing Da, Fish and Pork Aap are the most popular foods among the local people which is available in the local market but rarely found in restaurants. New menu with good taste which included Kao Gun Jin, Kao Ram Fean and Kao Puk Nga Dum, among others, were the food which were challenging sell in local restaurants.

Moreover, some recipes reported by the laboratory researchers were rich in herb ingredients with healthy essential nutrients and antioxidants. For instance, Pak Chieng Da is high in diabetic protection.

2) The result of the study showed that the five stages of the Knowledge Management Model of Thai Local Food in the Northern Tourism could be used as a guide to find out and verify in the knowledge construction.

3) The use of media development for Public Relation of Thai Local Food along the route of Northern Tourism could distribute information rapidly and reach the target audience directly. Most of the respondents were satisfied toward the overall media use. The following shows a high level:

- The opinion of the experts toward the media

The experts noted that the website was suitable to be used (4.69) in information searching, management of the local food and tourist route in the map, usefulness and application, and content and design, respectively. In case of the mobile application for smart phone and tablet, the suitability was also high (4.64) on usefulness, design and searching, content and content management, respectively.

- The media testing for local food promotion along the route of Northern Tourism in Thailand

The research found that the opinion of tourists toward the website was at a high level (3.98) as well as the mobile application in smart phone and tablet (3.96). The overall opinion showed that almost of the tourist preferred to search the information about local Thai food from mobile application in smart phone than website.

\section{Discussions AND CONCLUSIONS}

Thai local food knowledge in 14 provinces in the Northern region of Thailand has high potential for use in tourism promotion. The following discussion and suggestion were derived from the research.

Because the result showed that Northern local food have 
various taste and rich in culture with the story telling and legend, so the local tourism organization should apply such knowledge to promote local tourism using integrated media.

The strategy to introduce new Northern local food menu in restaurants may use website and the social media to give information about the recipes, ingredients, and health value to the public and tourist as well as in the restaurants on the route of Northern tourism of Thailand. Meanwhile, travel agencies and academic sectors should encourage Thai and foreigner tourists to learn and taste local Northern Thai food. The public and private sectors should be encouraged to conduct events and activities according to the needs of local community and relevant government officials.

The suitability of media using in the knowledge transferring and sharing stage came from the quality of media types which were compatible with the tourists preference. Therefore, travel agencies and relevant government officials should adopt the use of integrated media (website, mobile application, video, and publication) for Thai and foreigner tourists wherever they could be exposed the media in popular attractions such as airports, bus stations, and hotels.

Moreover, the research results confirmed that the tourists preferred to use the mobile devices, so the public and private sectors should promote and support a variety of new media such as the tourism websites and mobile application through the social media such as Facebook, Twitter, YouTube, Google+ and LinkedIn in smart phone, and tablet computer.

\section{ACKNOWLEDGEMENT}

The authors wish to thanks Department of Educational Technology, Faculty of Education, Kasetsart University for their support facilities in this project and Institute of Food Research and Development, Kasetsart University for the research team content analysis and review. This research project was financially supported by National Research Council of Thailand and Thailand Research Fund.

\section{REFERENCES}

[1] Policy of Taxation to Stimulate Tourist Industry of Thailand, Thammasart University, Bangkok, 2009
[2] S. Jewchareonsakul, "Tourist industry promotion: Aim to introduce thai foods matching with northern program's tours to serve sustainable tourism," Research Report Submitted to National Research Council of Thailand, Thailand Research Fund, Bangkok, Thailand, 2013.

[3] CNNGo. (September 7, 2011). World's 50 most delicious foods. [Online]. Available: http://travel.cnn.com/explorations/eat/readers-choice-worlds-50-mostdelicious-foods-012321

[4] N. Sompong, "Proactive promotion strategies and multimedia development and utilization in the Thai food to the world project," in Proc. International Conference on Developing Tomorrow's Leaders in Agriculture and Rural Development: Responding to the Challenges of Globalization, 2010, pp. 39-45, Los Banos, Laguna, Philippines: Searca, 2010.

[5] O. Henrie and M. Hedgepeth. (2003). Size is important in knowledge management. Journal of Knowledge Management Practice. [Online]. Available: http://www.tlainc.com/ articl53.htm

[6] I. Nonaka and H. Takeuchi, Hitosubashi on Knowledge Management, Singapore: Saik Wah Press, 2004.

[7] P. Vasri, Conference Document: Action Training for Knowledge Management, Kanjanaburi, July 2002.

[8] V. Panich, Knowledge Management, Bangkok: Sukkapapjai Printing, 2002 .

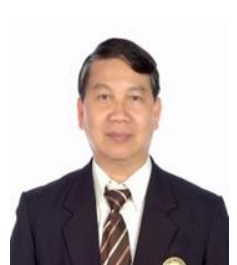

Narong Sompong is an associate professor at the Department of Educational Technology, Faculty of education, Kasetsart University, Bangkok, Thailand. He received Ph.D. in development communication in 1991 from the University of the Philippines, Los Banos, M.Ed. in educational technology in 1976 and B.Ed. in secondary education in 1973 from Srinakarinwirot University, Bangkok. $\mathrm{He}$ is the chairman of Doctoral Degree Special Program in educational communications and technology. His researches concern in the field of educational technology, e-learning, instructional media design and production, knowledge management in education, multimedia design and development, television program and photography in education.

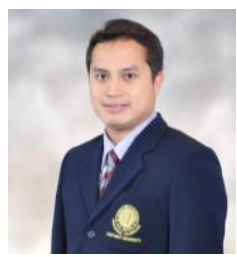

Nattaphon Rampai received Ed.D. in educational technology, in 2011, M.Ed in educational technology in 2005 from Kasetsart University in Bangkok, Thailand B.Sc.Ind.Ed in industrial education from King Mongkut Thonburi University of Technology, Bangkok in 2003. He is a lecturer in the Department of Educational Technology, Faculty of Education, Kasetsart University, Thailand. He works as an assistant dean, Faculty of Education and the Secretary, Department of Educational Technology. His researches involve knowledge management in education, web-based instruction, virtual reality learning and ICT for education. 